\title{
THE ATTRIBUTE ASSESSMENT PROCESS AT THE UNIVERSITY OF MANITOBA
}

\author{
Sandra Ingram, Jillian Seniuk Cicek, and Nariman Sepehri \\ Faculty of Engineering, University of Manitoba, Winnipeg, MB, Canada R3T 5V6 \\ Corresponding author E-mail address: Sandra.Ingram@ad.umanitoba.ca
}

\begin{abstract}
This paper describes a recent effort at the University of Manitoba to identify how CEAB graduate attributes are manifested and measured in the engineering curriculum. For this study, four attributes were chosen: Investigation and Design, part of the engineering hard skills, and Professionalism and Lifelong learning as representative of the professional skills of engineering. One third year course each from the Departments of Biosystems, Civil, Mechanical, and Electrical and Computer Engineering were selected to examine the four target attributes during the 2011 Fall term. The respective instructors were involved in completing a self-administered checklist with the intent to survey instructors' understanding of how the four CEAB attributes were manifest in their courses, and mapping the targeted attributes to the identified courses. Results show that there is much more research needed in this area, with continued emphasis on the manifestation of the twelve CEAB attributes in individual courses, as well as research on student proficiency, and methods of communicating assessment. Although this study did not set out to compare the attributes to one another, there was some evidence that of the four attributes being measured across the four courses, hard skills were more prominently assessed than professional skills.
\end{abstract}

Keywords: outcomes-based learning; attribute assessment; summative assessment; accreditation.

\section{INTRODUCTION}

In 2009, the Canadian Engineering Accreditation Board (CEAB) identified twelve attributes in which all graduating engineers were expected to be proficient, and called for all Canadian Engineering programs to evaluate these attributes in their graduating engineers [5]. Assessment of the graduate attributes was not only to demonstrate proficiency in graduating engineers, but to assess engineering programs "for the purpose of program improvement" [1]. The twelve attributes identified by CEAB necessary for graduating engineers include: (1) A knowledge base for engineering; (2) Problem analysis; (3) Investigation; (4) Use of engineering tools; (5) Design; (6) Individual and team work; (7) Communication skills; (8) Professionalism; (9) Impact on society and environment; (10) Ethics and equity; (11) Economics and project management; (12) Lifelong learning [5]. The work that is required for Canadian engineering programs to earn accreditation from the $\mathrm{CEAB}$ is not only "extremely thorough and time-consuming, involving a multi-year timeframe and the exhaustive collection, organization and analysis of information" [3], but it also marks the implementation of "a system to measure and continuously improve graduate outcomes... [which] means that accreditation is no longer an episodic task...but is now an ongoing continuous activity" [3]. Establishing attributes at the onset of an engineering program shifts teaching and learning from an input-based methodology and evaluation system to an outcomes-based methodology and assessment process [14] [15].

In the field of engineering education, the broadening educational paradigm of assessment is relatively new. "While it can be argued that student learning has always been the goal of higher education, emphasis for understanding and measuring student learning, rather than teaching, is a much newer phenomenon" [10]. Not only are engineering educators focusing on evolving their methods of assessment, but they are also tackling defining attributes for the "soft" or, as they will be referred to in this paper, the "professional skills" [12] of engineering so that they can effectively teach and assess these outcomes [7]. The hard skills of engineering include the first five CEAB graduate attributes, and the professional skills of engineering make up of the last seven.

At the University of Manitoba, the work on outcomesbased education and assessment is very recent. Extensive consultation with University of Manitoba academics and the University Teaching services, and broad reviews of a variety of literature are ongoing in this process. The first steps included developing learning outcomes for courses, mapping these learning outcomes to the twelve CEAB graduate attributes, identifying the learning foci (also known as learning objectives) for each attribute, and then developing as many indicators as possible for the learning foci so as to provide multiple ways for instructors to teach and assess the learning outcomes.

This study represents one facet of the work being done in Engineering at the University of Manitoba on the twelve $\mathrm{CEAB}$ graduate attributes. The long term objectives of this research are to: (i) investigate how the $\mathrm{CEAB}$ attributes manifest in the University of Manitoba engineering curriculum; (ii) reflect on how they are measured; and (iii) explore the extent to which the 
measurable attributes result in course content proficiency. This paper reports on the initial investigation of four senior level engineering courses and four different attributes: Investigation, Design, Professionalism and Lifelong Learning, and the extent to which these courses measure these attributes. It is a largely exploratory study, and although our findings group all four courses together when looking at the individual attributes, it is our intention that the findings for each course be considered individually rather than comparatively. This paper should be viewed as an initial step in a series of steps as the faculty moves towards a curriculum constructed by outcomes-based teaching and assessment practices.

\section{METHODS}

Four CEAB graduate attributes were chosen in the summer of 2011 to see how they were manifest and measured in the Faculty of Engineering curriculum. The selected attributes were: Investigation, Design, Professionalism and Lifelong Learning. The first two were chosen to reflect the more traditional, hard skills of engineering, while the latter two were selected to represent what are often considered to be the less quantifiable or easily measured engineering professional skills.

Subsequently, one course from each of the four departments that make up the Faculty of Engineering at the University of Manitoba was examined to investigate the attributes in a representative fashion. In order to have a common cohort for analysis, all courses were offered at the third year level in the Fall of 2011 and included BIOE 3580 (Design Trilogy II); CIVL 3760 (Structural Analysis); MECH 3980 (Mech Eng'g Lab); and ECE 3720 (Introductory Power and Machines). The above courses were selected in consultation with the four department heads and based on the willingness of the instructors.

Research was conducted in two parts. First, at the beginning of the Fall 2011 term, each instructor was provided with a checklist consisting of the targeted attributes and their associated learning foci and indicators. (Appendix A provides an excerpt from this 24 page checklist.) This checklist was constructed with the intent to survey instructors' understanding of how the four $\mathrm{CEAB}$ attributes were manifest in their courses, and was self-administered. Instructors were asked to identify which attributes/indicators they formally assessed in their courses; identify attributes/indicators they taught but which had no formal assessment process; and/or identify the attributes/indicators they did not teach or correspondingly assess at all. If instructors did assess the attributes/indicators, they were then asked to show how that assessment took place (e.g. through quizzes, tests, exams, lab reports, presentations, projects or other means). For those attributes/indicators that were formally assessed, instructors were asked whether the results were communicated to students and in what manner (e.g. raw scores, feedback sheets, rubrics).

The second part of the study took place towards the end of the term or once the courses were complete. Instructors were asked to map one or more of the attributes/indicators to a specific summative assessment activity in their course (e.g. test, exam, presentation, lab report, project or other assignment), and report on students' marks for those specific indicators.

\section{RESULTS AND DISCUSSION}

Results from analysis of the checklists reveal a number of findings about instructors' understanding of the attributes/indicators they identified teaching and assessing. As stated in the introduction, the findings of this study are meant to be considered individually for each course, even though for this paper, the results group the courses together by attribute. The professional skills will be discussed first.

Professionalism and Lifelong Learning attributes were formally assessed through most of the four courses, but at a relatively marginal level. Professionalism, the attribute which refers to "an understanding of the roles and responsibilities of the professional engineer in society, especially the primary role of protection of the public and the public interest," has two associated learning foci: etiquette, responsibility and practice; and safety and risk management. There are six indicators connected to the first focus and seven connected to the second. BIOE 3580, CIVL 3760 and MECH 3980 course instructors reported assessing indicators related to the learning focus of etiquette and responsibility and practice within Professionalism, formally assessing approximately one third of the indicators as seen in Fig. 1.

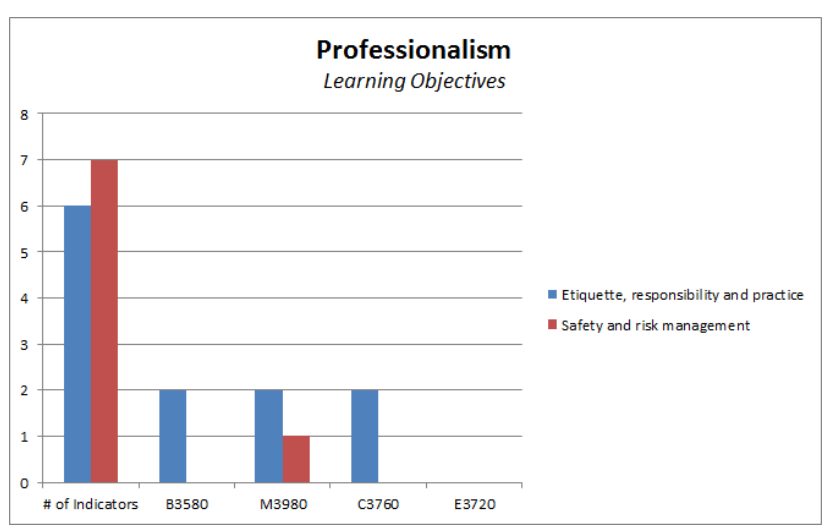

Fig. 1. Assessment of Professionalism

Less evident was the learning focus of safety and risk management within Professionalism, with the $\mathrm{MECH}$ 3980 instructor reporting assessment of this focus through 
one indicator, namely "understands workplace safety principles in university context (WHMIS training)." The instructor for ECE 3720 did not report formally assessing Professionalism using the above mentioned learning foci and indicators.

With regards to the attribute Lifelong Learning, which refers to "an ability to identify and to address [students'] own educational needs in a changing world in ways sufficient to maintain their competence and to allow them to contribute to the advancement of knowledge," there are four associated learning foci: understanding individual learning and needs; acquiring and evaluating information; commitment to lifelong learning; and managing knowledge. None of the four engineering instructors of the courses represented in this study reported measuring indicators associated with either the learning foci of understanding individual learning and needs or commitment to lifelong learning as seen in Fig. 2. The MECH 3980 instructor did report assessing a minimal amount of the learning foci managing knowledge and acquiring and evaluating information, while the BIOE 3580 co-instructors measured approximately one third to one half of those two learning foci. Thus, most indicators with respect to the attributes Professionalism and Lifelong Learning were found to be either inapplicable to the respective courses or marginally assessed.

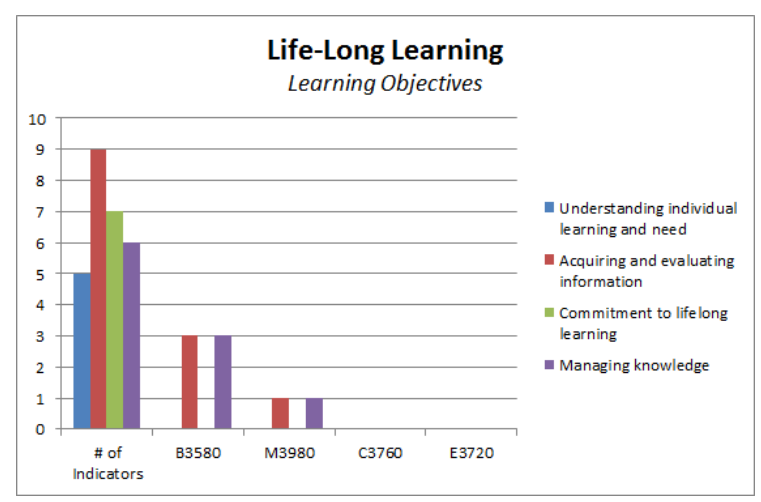

Fig. 2. Assessment of Lifelong Learning

Results from the analysis of the more traditional engineering hard skill attributes, Investigation and Design, also indicate some trends. There are four learning foci associated with Investigation: planning and information gathering; experimentation; data analysis/interpretation; and synthesis of results. Instructors from all four courses from the respective departments reported measuring these indicators to varying degrees, as seen in Fig. 3. The BIOE 3580, MECH 3980, CIVL 3760 and ECE 3720 instructors each reported measuring indicators associated with the learning focus planning and information gathering. The learning foci experimentation, data analysis, and to a lesser extent synthesis of results, were assessed in MECH 3980, CIVL
3760 and ECE 3720, with a stronger emphasis on experimentation in ECE 3720, and data analysis and interpretation in MECH 3980.

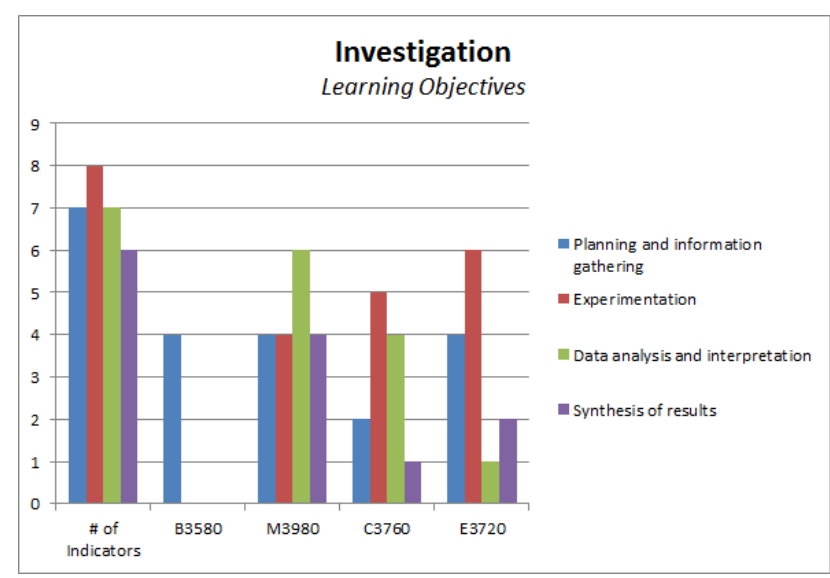

Fig. 3. Assessment of Investigation

The Analysis of the Design attribute includes seven learning foci: process overview; problem definition; identification and use of resources; generating ideas and design concepts; refinement and finalizing design; implementation; and evaluation. The BIOE 3580 course content was found to measure most of these foci as seen in Fig. 4, with the exception of implementation. The MECH 3980 instructor assessed the learning focus identification and use of resources; the CIVL 3760 instructor measured both learning foci identification and use of resources and process overview. The ECE 3720 instructor reported not teaching the Analysis of Design attribute as it was not a focus of the course.

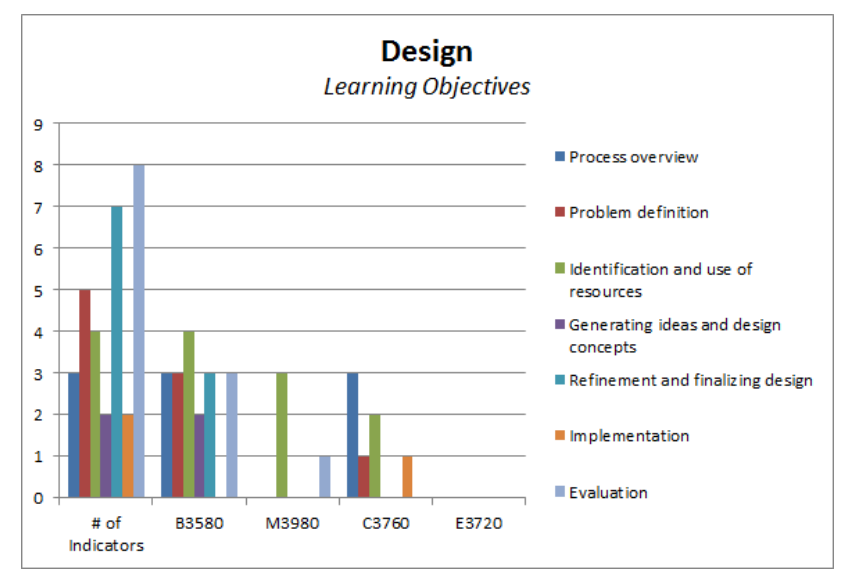

Fig. 4. Assessment of Design

Towards the end of the term and after the instructors had completed their checklists, they were then asked to map one or more of the attribute indicators to summative assessment activities in their courses, and share students' marks for those specific indicators. The intent was for 
instructors to look for examples of attributes being measured, and to tease out students' proficiency in assignments related to the targeted indicators.

For the most part, the hard skill attributes were found to be the most measured. In Figs. 5-7, the y-axis indicates the number of students in each bin, and the $\mathrm{x}$-axis is the mark distribution. In three courses, BIOE 3580, CIVL 3760 and $\mathrm{MECH}$ 3980, instructors were able to map multiple indicators within a single assignment. In one case, the BIOE 3580 co-instructors were able to measure both the hard and professional skills together through a single literature review assignment. This assignment assessed the Investigation attribute (the planning and information gathering learning focus and one indicator associated with it) as well as the Lifelong Learning attribute (the acquiring and evaluating information learning focus and one indicator associated with it). Twothirds of students in the class (12 out of 18) scored a B or above (3.0 Grade Point Average (GPA) or above out of a potential 4.5 GPA) on one indicator (identifies appropriate technical literature and other information sources to meet a need), and 14 out of 18 students scored B (3.0 GPA) or above on the other (makes accurate use of technical literature and other sources to meet a need).

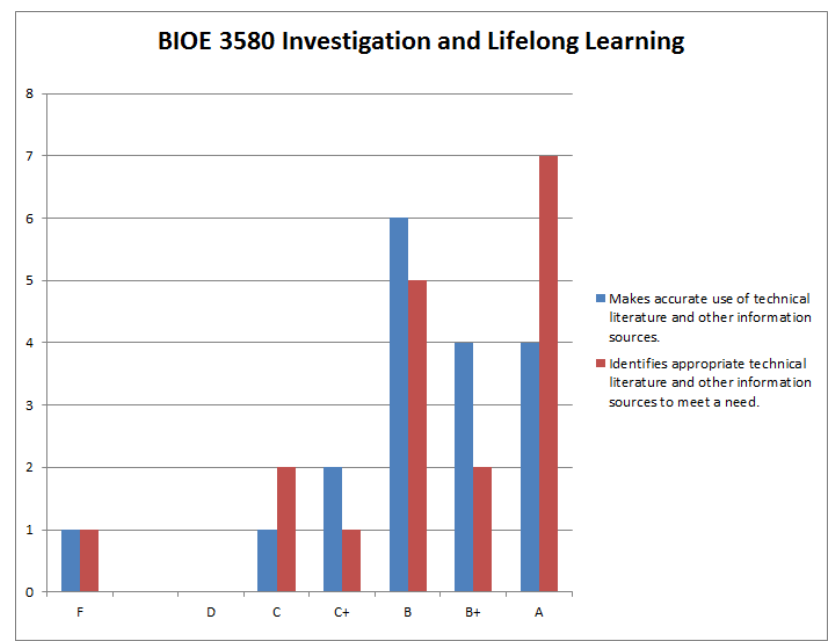

Fig. 5. Mapping of Attributes in BIOE 3580

In MECH 3980, four indicators associated with the attribute Investigation (experimentation) were mapped through a single lab assignment as seen in Fig. 6 . Seventy-four out of 76 students in the class scored B (3.0 GPA) or higher on the indicator "recognizes the characteristics of and distinguishes between experimental investigation and theory." Sixty-eight scored a B (3.0 GPA) or above on the indicator "describes limitations of theory," while 72 students scored B (3.0 GPA) and above on the indicator "applies mathematical and scientific principles to predict behavior of systems and processes." Finally, 74 scored B (3.0 GPA) or above on the indicator "understands the strengths/weaknesses of bench-scale experiments, field scale experiments and simulations."

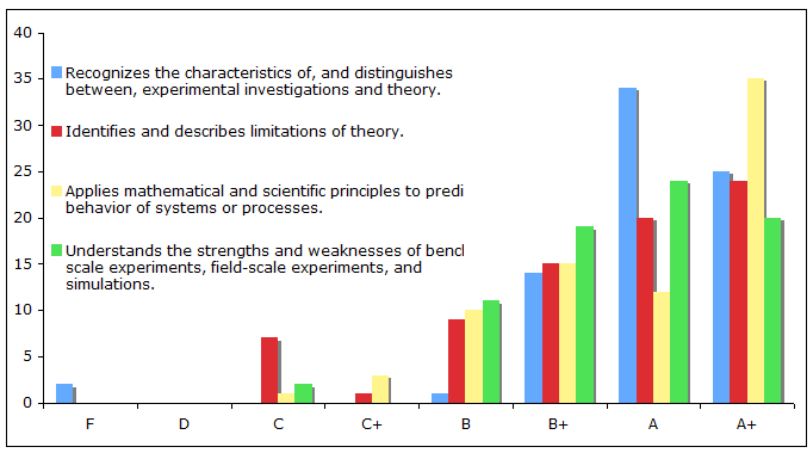

Fig. 6. Mapping of Investigation Attribute in $\mathrm{MECH} 3980$

In CIVL 3760, three learning foci associated with Design (process overview, problem definition and identification) were measured through a bridge design project and mapped as shown below. Out of a class of sixty-four students, all students scored B+ (3.75 GPA) or higher on the indicator "documents required outcomes," and a B (3.0 GPA) or higher on the indicator "uses variety of methods to explain, interpret and assess information."

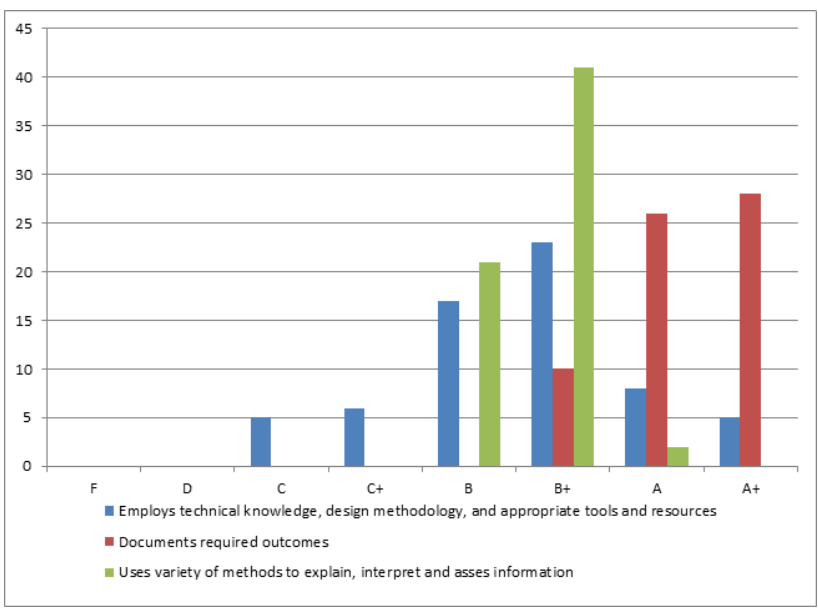

Fig. 7. Mapping of Design Attribute in CIVL 3760

Finally, in ECE 3720, two indicators associated with Investigation (experimentation) were mapped. The first was a numerical problem in a mid-term test where students used theory to predict the behavior of a relatively complex transmission system as shown in Fig. 8. Out of 21 students, 16 scored a B (3.0 GPA) or above on this question (marks 11-15). The second graph shows how students performed in a lab where they had to follow a standard procedure to obtain the parameters of a transformer. Out of 22 students, 20 obtained a B (3.0 GPA) or above (marks 8-10). 


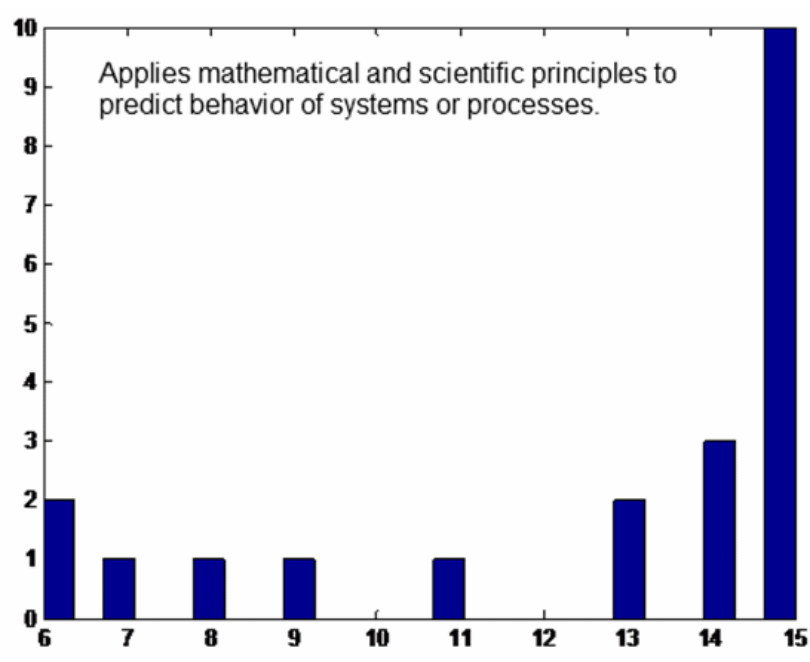

Fig. 8. Mapping of Investigation Attribute in ECE 3720 (Mid-term Test)

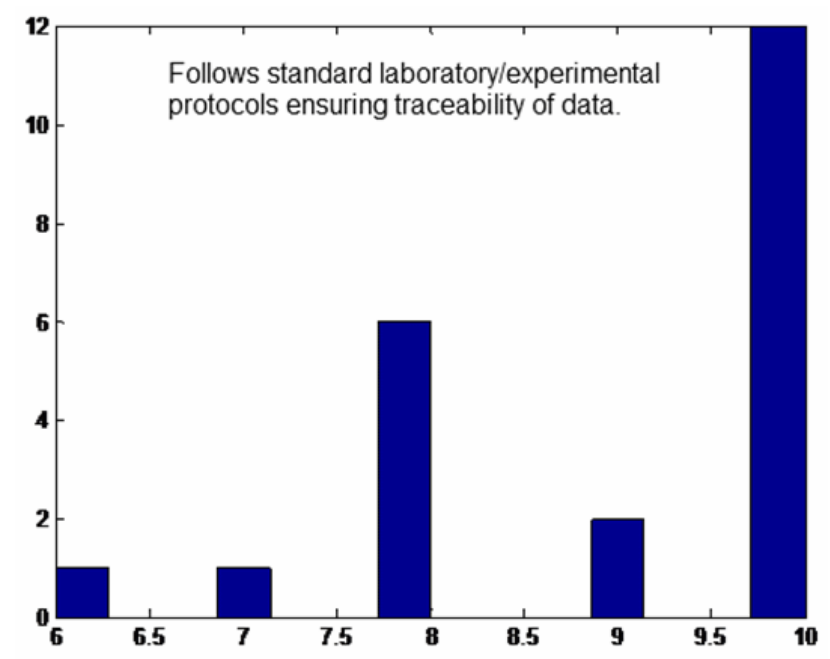

Fig. 9. Mapping of Investigation Attribute in ECE 3720 (Lab Report)

We also asked how instructors communicated the results of their assessments to their students. In two out of the four courses, CIVIL 3760 and ECE 3720, students were given their results (design reports, mid-term tests and lab reports) in the form of marks. In MECH 3980 and BIOE 3580, instructors used mark sheets/rubrics to convey feedback. When rubrics were used, the wording was reflective of that used in the CEAB attribute/indicator descriptions (see Appendix B for one example of a rubric utilized).

\section{CONCLUSIONS}

Similar to other Canadian universities, the attribute assessment process at the University of Manitoba is in its early stages as instructors progressively learn how their course material aligns with the twelve $C E A B$ graduate attributes and their associated learning foci and indicators. This study, based largely on instructors' responses to a self-administered checklist, has drawn attention to four targeted attributes representative of both the hard skills and professional skills of engineering, to explore how they were manifest and measured in four, third year undergraduate courses taught at the University of Manitoba in the Fall of 2011. Working with teaching and assessing the CEAB graduate attributes is a learning process, and this study has re-emphasized that.

Initial findings point to evidence that instructors are teaching and assessing the four targeted attributes to varying degrees in the implementation of their course material, with more evidence of assessment of the hard skills of engineering. While the professional skills were not formally assessed to the same extent as the hard skills, it is noteworthy that instructors found that they addressed the professional skills in their teaching, but may require a more formalized approach in future iterations of their courses. This validates research done previously on the prominence of hard skill assessment in comparison to professional skill assessment in the engineering curriculum.

In addition to these findings, it was found that a large percentage of students scored B (3.0 GPA) or above in the targeted indicators measured. More research is required to define levels of student learning proficiency for each attribute and their individual indicators. Similarly, assessment communication methods and their effectiveness offer another potential area of research. Detailed rubrics illustrate how levels of proficiency in attributes/indicators can be explicitly communicated to students.

Finally, this study provided an opportunity for a group of instructors to reflect on their teaching and assessment practices in an ongoing effort to understand how their methods mesh with CEAB accreditation goals.

As stated previously, this study is a small part of a larger research project. This research process will continue, with the intent of looking at four more $\mathrm{CEAB}$ attributes in senior (third and fourth year) courses during the 2012 - 2013 academic year, and the final four CEAB attributes in senior courses during the 2013 - 2014 academic year. In this way, we hope to achieve some understanding of how the twelve CEAB graduate attributes are manifest and measured in senior year courses in the Faculty of Engineering at the University of Manitoba. 


\section{ACKNOWLEDGMENTS}

The authors would like to thank the following instructors for their work in helping us obtain these data and for sharing their valuable input and resources: Dagmar Svecova, Paul Labossiere, Kris Dick and Shaahin Filizadeh.

\section{References}

[1] Brock E. Barry and Matthew W. Ohland, "Applied ethics in the engineering, health, business, and law professions: A comparison," Journal of Engineering Education, vol. 98, no. 4, pp. 377-388, 2009. Available from http://www.jee.org/2009

[2] Denny C. Davis, Kenneth L. Gentili, Michael S. Trevisan, and Dale E. Calkins, "Engineering design assessment processes and scoring scales for program improvement and accountability," Journal of Engineering Education, vol. 91, no. 2, pp. 211-221, 2002. Available from http://www.jee.org/2002

[3] Steven K. Dew, Mathieu Lavoie, and Ashley Snelgrove, "An engineering accreditation management system," in Proc. CEAA Canadian Engineering Conf., CEEC11, Andy Fisher (ed.) (St. John's, NL; 6-8 June 2011), pp. 5, 2011.

[4] Brian Frank and Susan Fostaty Young, "What can our students do: Year 2 of graduate attribute assessment at Queen's University," in Proc. CEAA Canadian Engineering Conf., CEEC11, Andy Fisher (ed.) (St. John's, NL; 6-8 June 2011), pp. 6, 2011.

[5] Brian Frank, Susan McCahan, K. Christopher Watts, Susan Fostaty Young, Peter Ostafichuck, Peter Wolf, and Nasser Saleh, "Engineering graduate attribute development (EGAD) project," in Proc. CEAA Canadian Engineering Conf., CEEC11, Andy Fisher (ed.) (St. John's, NL; 6-8 June 2011), pp. 3, 2011. Available from http://engineering.queensu.ca/egad

[6] Sheldon, I. Green, "Student assessment precision in mechanical engineering courses," Journal of Engineering Education, vol. 94, no. 2, pp. 273 - 278, 2005. Available from http://www.jee.org/2005

[7] S. Jiusto and D. Di Biasio, "Experiential learning environments: Do they prepare our students to be self-directed, life-long learners?," Journal of Engineering Education, vol. 95, no. 3, pp. 195-204, 2006. Available from http://www.jee.org/2006.

[8] Susan McCahan, Grant Allen and Lisa Romkey, "Development of the graduate attribute quality assurance process at the University of Toronto," in Proc. CEAA Canadian Engineering Conf., CEEC11, Andy Fisher (ed.) (St. John's, NL; 6-8 June 2011), pp. 6, 2011.

[9] Barbara M. Olds, Barbara M. Moskal and Ronald L. Miller, "Assessment in engineering education: Evolution, approaches and future collaborations," Journal of Engineering Education, vol. 94 , no. 1 , pp. 13-25, 2005. Available from http://www.jee.org/2005

[10] Donna M. Qualters, Thomas, C. Sheahan, Emanuel J. Mason, David S. Navick and Matthew Dixon, "Improving learning in first-year engineering courses through interdisciplinary collaborative assessment," Journal of Engineering Education, vol. 97, no. 1, pp. 37-45, 2008. Available from http://www.jee.org/2008

[11] Robert J. Roselli and Sean P. Brophy, "Effectiveness of challenge-based instruction in biomechanics," Journal of Engineering Education, vol. 95, no. 4, pp. 311-324, 2006. Available from http://www.jee.org/2006

[12] Larry J. Shuman, Mary Besterfield-Sacre and Jack McGourty, "The ABET "professional skills" - can they be taught? Can they be assessed?" Journal of Engineering Education, vol. 94, no. 1, pp. 41-55, 2005. Available from http://www.jee.org/2005

[13] Carol Siri Johnson, "The analytic assessment of online portfolios in undergraduate technical communication : A model," Journal of Engineering Education, vol. 95, no. 4, 279287, 2006. Available from http://www.jee.org/2006

[14] Neelam Soundarajan, "Preparing for accreditation under EC 2000: An experience report," Journal of Engineering Education, vol. 91, no. 1, pp. 117-123, 2002. Available from http://www.jee.org/2002

[15] Peter Wolf and Warren Stiver, "Graduate attributes: Intentional mapping and assessment portfolios," in Proc. CEAA Canadian Engineering Conf., CEEC11, Andy Fisher (ed.) (St. John's, NL; 6-8 June 2011), pp. 4, 2011.

\section{APPENDIX A: Sample Check List}

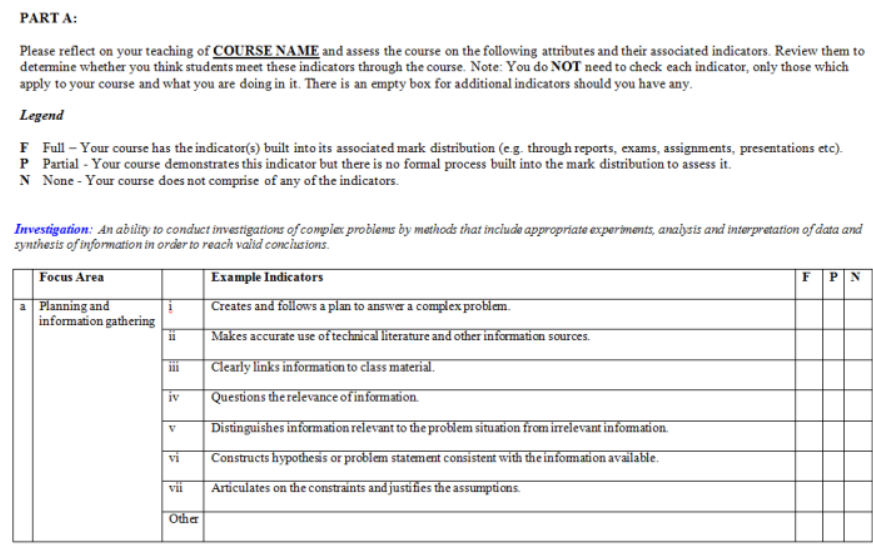


APPENDIX B: MECH 3980 Lab 3 Report Score Sheet

\begin{tabular}{|c|c|c|c|c|}
\hline & & & Score & Comments \\
\hline 1 & Formatting & $/ 15$ & & \\
\hline 2 & Introduction & $/ 10$ & & \\
\hline 3 & $\begin{array}{l}\text { Recognizes the } \\
\text { characteristics of, and } \\
\text { distinguishes between, } \\
\text { experimental investigations } \\
\text { and theory. }\end{array}$ & $/ 15$ & & \\
\hline 4 & $\begin{array}{l}\text { Identifies and describes } \\
\text { limitations of theory. } \\
\text { (Sources of error) }\end{array}$ & $/ 15$ & & \\
\hline 5 & $\begin{array}{l}\text { Applies mathematical and } \\
\text { scientific principles to } \\
\text { predict behavior of systems } \\
\text { or processes. (Analytical } \\
\text { model truss and proving } \\
\text { ring) }\end{array}$ & $/ 15$ & & \\
\hline 6 & $\begin{array}{l}\text { Understands the strengths } \\
\text { and weaknesses of bench- } \\
\text { scale experiments, field- } \\
\text { scale experiments, and } \\
\text { simulations. }\end{array}$ & $/ 15$ & & \\
\hline 7 & $\begin{array}{l}\text { Conclusions and } \\
\text { Recommendations }\end{array}$ & $/ 15$ & & \\
\hline
\end{tabular}

